Original Research

\title{
An Analysis of Recycling Performance for Achieving a Zero-Emission Society
}

\author{
Yi-Tui Chen* \\ Department of Health Care Management, National Taipei University of Nursing \\ and Health Sciences, Taipei, Taiwan
}

Received: 29 June 2017

Accepted: 21 November 2017

\begin{abstract}
Considering the management objectives of sustainable development, this paper examines and compares the recycling performance of various waste fractions in Taiwan in the context of sustainable development and develops a simple calculation method to define recycling performance for each waste fraction. In this paper, recycling performance is defined as the ratio of waste recycled to waste generated. The result finds that the recycling performance of waste metals was the highest, followed by waste glass and waste paper. This paper also finds that the recycling performance of food waste increased with the mass of food waste until it reached an optimum and dropped off with additional increases in mass of food waste past in the optimum. In consideration of a large amount of food wastes generated from productive institutions such as wholesalers, retailers, and restaurants, etc., this paper suggests 2 instruments to reduce the generation rate of food waste and increase recycling performance at the source: 1) a tax on food waste generated in the production process and 2) requiring production facilities to install affiliated digestion or composting plants for recycling of food waste. As for reducing consumptive food waste, this paper emphasizes the important role of environmental education for the public to engage in green consumption.
\end{abstract}

Keywords: municipal solid waste, recycling performance, food waste, recyclables

\section{Introduction}

Traditional municipal solid waste (MSW) management assumes that the government has sufficient capacity to manage pollution by employing appropriate policies to clean up accumulated contamination and control pollution emissions at a regulated level through either a command-and-control system or economical instruments. By the 1990s, the concept of a zero-emission society was promoted by many researchers. For example, Miller [1] proposed a low-waste society model based on

*e-mail: yitui@ntunhs.edu.tw the 3 thermodynamic laws and concludes "the best longterm solution to our environmental and resource problems is to shift from a society based on maximizing matter and energy flow (throughput) to a sustainable low-waste society or earth-wisdom society." The aims of sustainable development may provide a healthy future for humanity if social, economic, and environmental development can be coordinated and accompanied by a reduction in poverty and inequality [2]. It is characterized by "living within the ecological limits and meeting the needs of everyone" [3].

A zero-emission society is formed as part of Taiwan's environmental policy that emphasizes the important role of recycling and reduction at the source through the social promise of clean production and green consumption and 


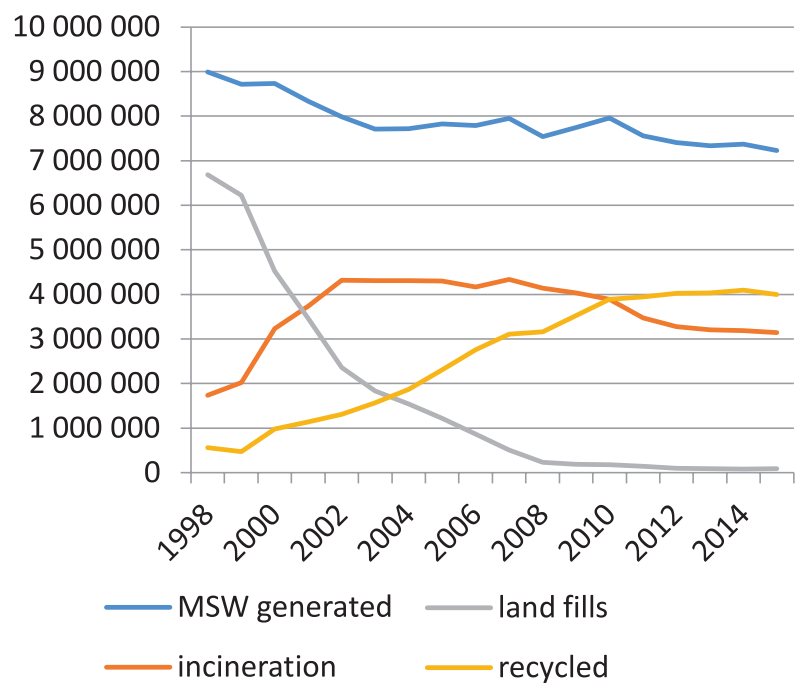

Fig.1. Trend of MSW generated, incinerated, landfilled, and recycled in Taiwan during 1998-2015.

Source: Taiwan EPA (2016)

an efficient system of management practice [4]. Such an environmental policy emphasizes the important role of recycling and sustainable consumption behaviors. In the past, many researchers have presented the relevant studies in association with the issue of municipal solid waste (MSW) [5-8]. For example, Chen [6] analyzes the relative efficiency at each stage of MSW management practice by using the DEA (data envelopment analysis) technique. Many researchers have suggested the source separation at home for municipal solid waste management in order to enhance recycling performance and to reduce processing costs [9-11]. In practice, many countries have accepted source separation as part of their environmental policies for municipal solid waste management. However, the evaluation of recycling performance for each fraction in MSW is not spread extensively in prior studies. Thus, the purpose of this paper firstly is to compare the recycling performance for each waste fraction based on the historical data provided by Taiwan's Environmental Protection Agency (EPA). Based on the outcome of recycling performance for each waste fraction, this paper attempts to explain the potential causes of recycling performance for each waste fraction and to present some improvement strategies for policy makers.

\section{Research Methods}

According to the current management practice regulated by Taiwan's EPA, recyclable wastes include waste paper, waste metal can, waste plastics, and food wastes. In order to make a preliminary standing on the status of Taiwan's MSW management practice, Fig. 1 demonstrates the trend of MSW generated and MSW recycled. The total MSW generated has been in continuous decline, decreasing from 8,992,000 tons in 1998 to 7,229,000 tons in 2015. The per capita MSW generated in 2015 was reduced by $63.56 \%$ compared to 1998, and reached $0.85 \mathrm{~kg} /$ day/capita [12].

In contrast, the MSW recycled increased from 149,876 tons in 1998 to $3,993,101$ tons in 2015. Fig. 1 demonstrates that MSW recycled kept an increasing pattern during 1998-2010, but started to be flat after 2010 due to decreased MSW generated. The MSW recycled accounts for about $55.20 \%$ in 2015 . This implies that the recycling performance for all recyclables works well in past decades.

Considering the fact that data of recycling amounts for some waste fractions are not available, the analysis period for recycling performance in this paper covers 2003-2015 (Table 1). At the earlier stage, the amount

Table 1. The recycling amount for each waste fraction.

\begin{tabular}{|c|c|c|c|c|c|c|}
\hline & Paper & Metal & Plastics/Rubber & Glass & Textiles & Food \\
\hline 2003 & 543,995 & 225,039 & 111,385 & 93,477 & 16,438 & 168,601 \\
\hline 2004 & 715,072 & 335,394 & 140,875 & 112,201 & 21,610 & 299,265 \\
\hline 2005 & 892,618 & 409,357 & 178,555 & 133,453 & 27,508 & 464,201 \\
\hline 2006 & $1,090,346$ & 469,995 & 202,365 & 149,651 & 32,227 & 570,176 \\
\hline 2007 & $1,236,822$ & 547,701 & 218,714 & 184,227 & 41,367 & 662,791 \\
\hline 2008 & $1,328,827$ & 601,064 & 243,637 & 169,428 & 36,534 & 691,194 \\
\hline 2009 & $1,458,762$ & 623,485 & 286,954 & 182,533 & 38,640 & 721,472 \\
\hline 2010 & $1,574,593$ & 693,388 & 305,410 & 206,537 & 35,425 & 769,164 \\
\hline 2011 & $1,611,331$ & 696,227 & 301,317 & 220,547 & 33,755 & 811,199 \\
\hline 2012 & $1,717,287$ & 707,403 & 320,763 & 242,068 & 34,621 & 834,541 \\
\hline 2013 & $1,727,044$ & 770,825 & 333,856 & 257,924 & 36,642 & 795,213 \\
\hline 2014 & $1,768,517$ & 773,222 & 319,821 & 258,882 & 41,945 & 720,373 \\
\hline 2015 & $1,802,591$ & 758,200 & 311,960 & 252,332 & 44,044 & 609,706 \\
\hline
\end{tabular}


of waste paper and waste metal recycled is more than food wastes. In 2005 food wastes recycled exceeded waste metal, ranking second, followed by waste metal, plastics and rubber, and other waste fractions. After 2012 , recycled food wastes started to decline from 834,541 tons in 2012 to 609,706 tons in 2015 , while other waste fractions kept a constant growth or small fluctuation. In 2014 waste metal recycled with recycling amounts of 773,222 tons reversed the following situation and exceeded food waste by 52,849 tons ranking second among all waste fractions. In 2015 waste paper kept the leading position with a recycling amount of 1,802,591 tons, largely ahead of waste metal (758,200 tons), food waste (609,706 tons), waste plastics and rubber (311,960 tons), and other waste fractions.

In this paper, the recycling performance for each waste fraction $i$ is measured by:

$$
\theta_{i}=\frac{w_{r i}}{w_{g i}}
$$

...where $w_{r i}$ is the amount of $i$ th waste fraction recycled each year, $w_{g i}$ is the amount of $i$ th waste fraction generated, and $\theta_{i}$ is the recycling performance of the $i$ th waste fraction. The $i$ th waste fraction generated $w_{g i}$ is calcualted by:

$$
w_{g i}=w_{r i}+c_{i} w_{c}
$$

...where $w_{c}$ is the amount of MSW collected and delivered to either incinerators or landfills for final disposal, and $c_{i}$ is the composition of the $i$ th waste fraction in the MSW delivered for final disposal.

A typical analysis of MSW composition is given in Table 2 in order to understand the refuse characteristics. We find that the incombustible waste in MSW collected, including iron, metal, and glass, is greatly reduced - from $13.42 \%$ in 1998 to $2.06 \%$ in 2015 . This implies that the recycling of all this incombustible waste sorted as recyclables is successful.

In contrast, combustible waste increased from $86.58 \%$ in 1998 to $97.94 \%$ in 2015. Most of these combustible waste fractions did not change very much except for food wastes. The food waste in MSW increased from $18.29 \%$ in 1998 to $40.39 \%$ in 2015 . The high content of food waste in MSW may be attributed to relatively better performance of recycling on other recyclables. The other reason may be attributed to the particular property of food waste that may generate odor. As the collecting frequency for food waste is only 3 times a week and households are reluctant to store food waste at home overnight, food waste is packaged and disposed of as general waste by households.

\section{Results and Discussion}

The recycling performance for each waste fraction is calculated based on Eq. (1), and the result is listed in Fig. 2. The recycling performance for all recyclable waste tended to increase - from $16.50 \%$ in 2003 to $55.17 \%$ in 2015. This implies that recycling performance in Taiwan is significantly good. On the basis of each waste fraction, the recycling performance for glass, paper, and metal keeps a trend of continual growth, while plastics and rubber, textile, and food wastes execute an inverted U-shape, which increases and reaches a peak and then declines. Among the waste fractions, the recycling performance of waste metal ranks at the top. It increased from $58.61 \%$ in 2003 to $97.91 \%$ in 2015 . In fact, it has started to keep a gradual flat since 2008 by reaching $96.15 \%$. This implies that recycling performance for waste metal has reached to saturation state. The recycling of waste glass performs

Table 2. Physical composition of MSW in Taiwan on a wet basis (\%).

\begin{tabular}{|c|c|c|c|c|c|c|}
\hline & Year & 1998 & 2000 & 2005 & 2010 & 2015 \\
\hline \multirow{5}{*}{ Combustible } & Sub-total & 86.58 & 87.34 & 95.97 & 97.10 & 97.94 \\
\cline { 2 - 7 } & Paper & 32.77 & 26.37 & 38.64 & 39.57 & 34.69 \\
\cline { 2 - 8 } & Textile & 5.27 & 6.06 & 2.38 & 2.52 & 4.67 \\
\cline { 2 - 8 } & Garden trimmings & 4.81 & 3.36 & 1.93 & 1.74 & 1.61 \\
\cline { 2 - 8 } & Food wastes & 18.29 & 27.76 & 38.15 & 35.68 & 40.39 \\
\cline { 2 - 8 } & Plastics & 20.14 & 22.00 & 13.78 & 16.57 & 15.55 \\
\cline { 2 - 8 } & Leather and rubber & 0.83 & 1.35 & 0.43 & 0.51 & 0.54 \\
\hline \multirow{5}{*}{ Incombustible } & Other & 4.54 & 0.44 & 0.67 & 0.52 & 0.50 \\
\cline { 2 - 8 } & Subtotal & 13.42 & 12.66 & 4.03 & 2.90 & 2.06 \\
\cline { 2 - 8 } & Iron and metal & 5.66 & 3.73 & 1.14 & 0.67 & 0.50 \\
\cline { 2 - 7 } & Glass & 5.84 & 7.31 & 2.08 & 1.53 & 0.96 \\
\hline
\end{tabular}

Source: Taiwan EPA (2016) 


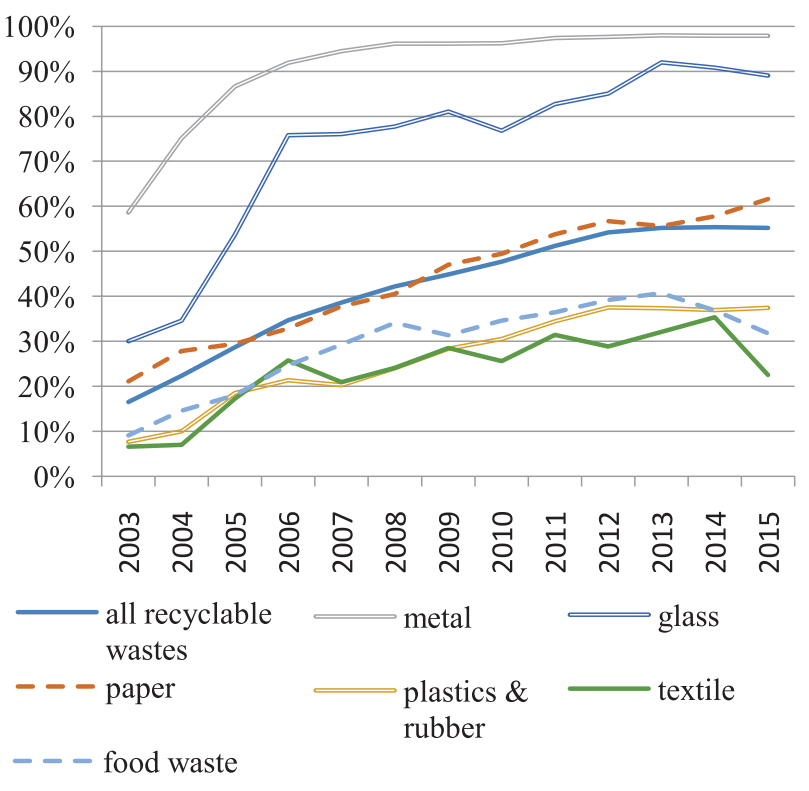

Fig. 2. Recycling performance for each waste fraction.

at the second place after waste metal, increasing from $30 \%$ in 2003 to $89.04 \%$ in 2015 . The recycling performance of waste paper ranked in third place, increasing from $21.13 \%$ in 2003 to $61.62 \%$ in 2015 .

Chen [13] indicates that the recycling behavior may take place spontaneously when waste metal can be sold at a good price. In the past decade, the market price of some waste recyclables is sufficiently high to encourage many private collectors to engage in recycling, while that of some other waste recyclables is comparatively low. For example, the price for scrap aluminum in the U.S. market is US\$ $0.25-0.35 / \mathrm{lb} \quad(\$ 0.55-0.77 / \mathrm{kg}$; source: crapmsc.com/our-pricing), and $\$ 0.06-0.08 / \mathrm{lb}$ for scrap cast iron $(\$ 0.132-0.176 / \mathrm{kg}$; source: rockawayrecycling. $\mathrm{com} /$ scrap-metal-prices). In the Chinese market prices are $\$ 60-90 /$ ton for waste paper and $\$ 300-500 /$ ton for scrap PET bottles (alibaba.com/showroom/waste-paper-prices. html).

In contrast, waste textiles rank at the bottom, with even its recycling performance increasing from $6.59 \%$ in 2003 to $22.57 \%$ in 2003 . The market price of waste textiles is very low at about NT\$1.00/kg (about US\$ $0.03 / \mathrm{kg}$ ), and thus very few collectors focus on the recycling of waste textiles. The recycling performance for both plastics and rubber and food wastes is almost the same. Before 2014, the recycling performance of food waste kept ahead of plastics and rubber. The recycling performance of plastics and rubber keeps rising, growing from $7.73 \%$ in 2003 to $37.47 \%$ in 2015 . The low recycling performance of plastics and rubber compared to other waste fractions may be attributed to its low market price. The current price is NT\$2.0/kg (about US\$ $0.67 / \mathrm{kg}$ ) for waste plastics, NT\$ $10 / \mathrm{kg}$ (about US\$ $0.33 / \mathrm{kg}$ ) for waste plastic containers. In addition, the incineration of waste plastics or rubber can generate electricity for sale and may be more beneficial to the environment [5].
On the other hand, the recycling performance of food wastes increased from $9.15 \%$ in 2003 to $39.18 \%$ in 2012 , and then a peak of $40.73 \%$ in 2013 , then falling quickly to $31.81 \%$ in 2015 . The recycling rate of food waste increased from 169,000 tons in 2003 to a peak of 835,000 tons in 2012 , and then decreased to 795,000 tons in 2013 and 610,000 tons in 2015. The decline of recycling performance for food waste after it reaches to a peak may be attributed to no market value of food waste and the difficulty in collecting it.

\section{Discussion}

This paper finds that the recycling of food wastes has declined in recycling amount and recycling performance since 2012. This implies that some hidden problems occur with the recycling of food waste. A variety of studies emphasize the importance of recycling and upgrading food waste for the recovery of useful products or energy. In brief, the major benefit of food waste recycling includes: 1) the saving of final disposal costs either by landfill or incineration, 2) the extension of service life for incineration plants, and 3) the avoidance of consequent impacts on the environment arising from landfill or incineration. As food wastes possess high organics and water content derived from kitchen residue, the incineration or landfilling of food waste may generate a significant impact on greenhouse gas emissions, hazardous gases (i.e., hydrogen sulfide, ammonia), and leachate [14-15]. The incineration process consumes a lot of energy and the life cycle of the incinerator could also be reduced due to the high content of moisture and salt in food waste.

Probably the most controversial pollutants from incinerator emissions are the categories of toxic chlorinated organics. Secondary emissions may occur at the landfill or incineration process for food waste disposal. Biogas is generated during the decomposition of organic waste in landfills, providing high impacts on the warming effects. Due to the significant greenhouse gas emissions from landfills or incinerators, it is necessary to mitigate future climate change impacts by diverting the waste disposal from incineration or landfilling to recycling [16].

Currently, no market value exists for food waste, and its storage may generate odor and becomes a nuisance. How to solve the problem is a vital factor in encouraging the recycling of food waste. Furthermore, Miller (1999, p. 67) suggests that the sustainable development of a society can be attained through "l) reusing and recycling most nonrenewable matter resources, 2) using potentially renewable resources no faster than they are replenished, 3) using matter and energy resources efficiently, 4) reducing unnecessary consumption, 5) emphasizing pollution prevention and waste reduction, and 6) controlling population growth." And thus, this paper suggests preventing the generation of food waste at the source, and then to reinforce the 


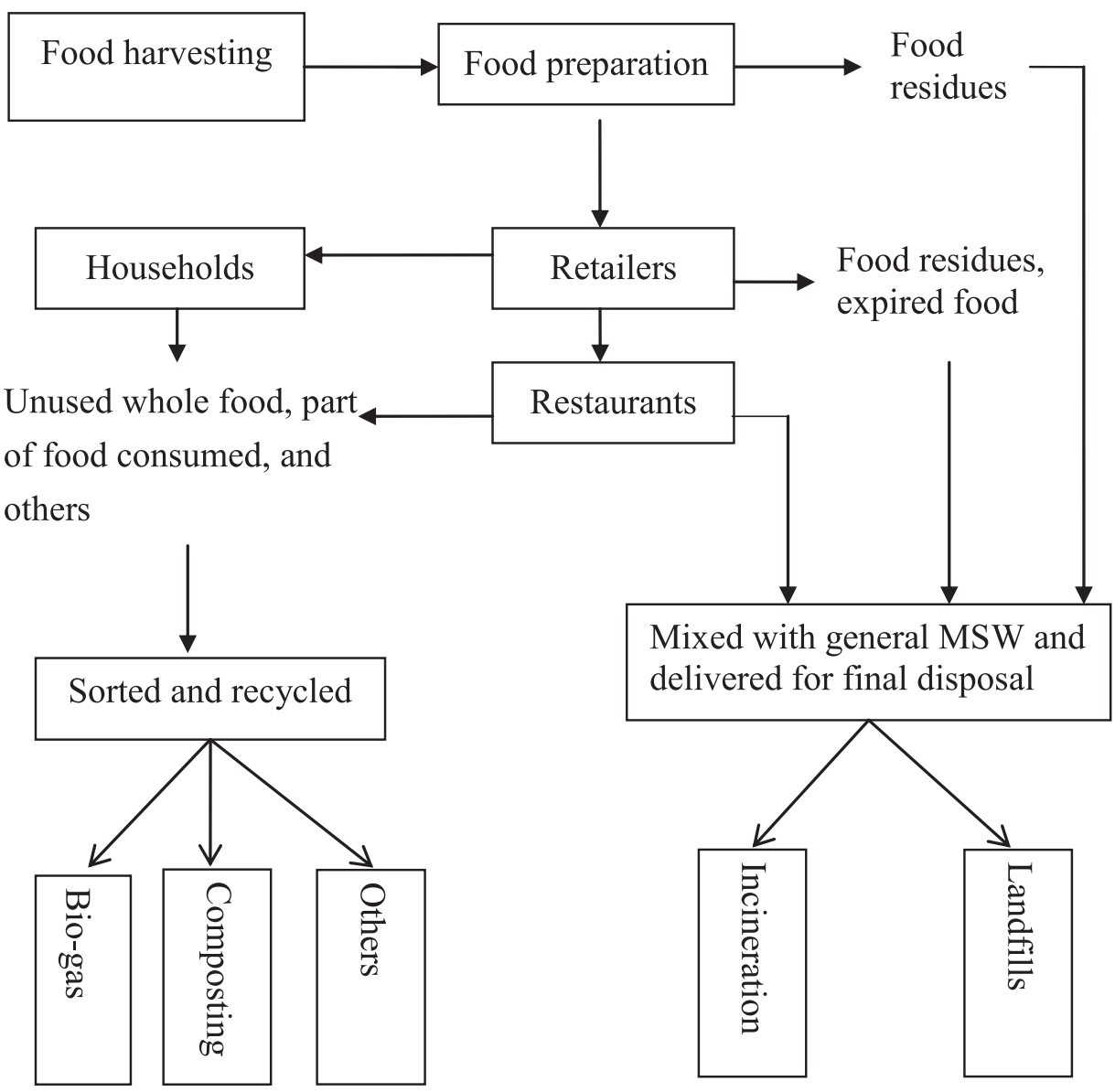

Fig. 3. Process of food waste generation.

application of food waste and to reduce the nuisance of food waste storage and collecting to encourage recycling.

\section{The Prevention of Food Waste Generation}

Basically, the generation process of food waste is illustrated in Fig. 3, in which it is classified into 2 categories: consumptive and productive. Productive food waste occurs at the stage of food preparation while consumptive food waste is generated at the stage of postpreparation and consumption. The consumptive source includes household kitchens, commercial restaurants, and restaurants in dormitories, schools, etc., and productive sources are specific to the relevant units in the food supply chain such as retailers, traditional markets, super markets, etc. The generation of productive food waste may occur at each stage in the food supply chain, including food storage, transportation, processing, at retailers, and final processing for food production in the kitchens of restaurants and households [17]. The European Commission [18] points out that $42 \%$ of total food waste is generated from households, $39 \%$ by the production and processing sector, $14 \%$ by the food service and catering sector, and $5 \%$ by the retail/wholesale sector.
A large quantity of edible food are lost at every stage of the food supply system, such as supermarkets or retailers. Eriksson et al. [19] analyzed the flow of fruit and vegetables at 6 Swedish retail stores and found that about $4.3 \%$ of delivered quantity is thrown away and seen as food waste. In general, the food residue generated from wholesale and retail systems is collected by private contractors and mixed with general MSW for final disposal either by incineration or landfills. The food wastes generated from food service institutions like restaurants are generally collected by private collectors and delivered to incinerators or landfills. In practice, household food waste separated from general MSW are collected by public collectors and delivered to the distribution center for advanced processing.

The empirical study of Segarra-Oña et al. [20] finds that managerial concern about environmental aspects may positively affect the adoption of proactive environmental strategies in the firm. The policy change is another factor to force a firm to switch their reaction strategies to proactive strategies [21]. As food wastes generated by productive units such as food processing plants, retailers, restaurants, etc. account for about 58\% [18], a policy change is required to motivate food producers to engage in proactive strategies to avoid or mitigate generating productive food waste. This paper suggests that 1) a tax imposition on the generation of productive food waste 
is suggested to encourage the reduction in food wastes and 2) productive units should be responsible for the disposal of food wastes by installing appropriate treatment systems.

On the other hand, the consumption pattern is important for affecting the total amount of solid waste generation in a society. This paper suggests that environmental education is required for consumers to engage in green consumption voluntarily.

\section{The Application of Food Waste}

Prior studies suggest that the reuse of excess food is not applicable due to the perishability of edible food and the mistrust of food quality [22]. In general, anaerobic digestion and aerobic composting are seen as two effective methods for treating various types of organic waste [23]. Digestion and composting technology for food waste has proven to be technically and economically viable in order to avoid the risk of pathogen infections. Thyberg and Tonjes [24] compare the environmental impacts of 7 scenarios for the disposal of food wastes and found that the anaerobic digestion scenario scored best, followed by tunnel composting. Theoretically, all degradable organic wastes can be digested or composted, but only a few types like food wastes and sludge are feasible for recovery by a dedicated plant.

The mechanical pre-treatment unit for the shredding of large objects through a belt conveyor is used to reduce the size of substrates before the removal of wastes that cannot be digested or composted. The size reduction can increase the surface area for microbial action and thus the decomposition can be easier for harder materials like fruit peel or wood. The food waste after shredding operation is mixed with some supplementary material as the composting process requires considerable quantities of supplemental material necessary to be mixed with the input material of food wastes to maintain good digesting or composting condition.

Food wastes are digested in the absence of oxygen (anaerobic bio-digestion), in which food wastes are converted to produce a methane-rich gas through microbial reaction. In other words, anaerobic microorganisms convert food waste into methane (CH4) and carbon dioxide (CO2). The conversion process for producing biogas is typically operated in closed reactors at elevated temperatures and facilitated by bacteria.

Theoretically, the production quantity of biogas follows the reaction formula expressed below:

$$
\begin{gathered}
C_{a} H_{b} O_{c} N_{d}+\left(\frac{4 a-b-2 c+3 d}{4}\right) H_{2} O \rightarrow\left(\frac{4 a-b-2 c-3 d}{8}\right) \\
C H_{4}+\left(\frac{4 a-b+2 c+3 d}{8}\right) C_{2}+d \mathrm{NH}_{3}
\end{gathered}
$$

In practice, biogas yield is affected by the type of feedstock and the substrate used in the biogas plant. The ingredient of food waste is a major factor for the operating performance of biogas production.
In contrast, food waste is mixed with supplementary materials and maintained at water content of $50-60 \%$ and $\mathrm{C} / \mathrm{N}$ ratio of 26-35 for producing compost. A regular windrow turning (about twice a week) can improve the speed of the process and product quality. A time span of several days to months is required for the aerobic waste composting process to stabilize the food waste under controlled aerobic conditions, depending on the process automation and inoculation. The maturated compost mix is moved to another space and waits for post fermentation that takes about 45-60 days. The final compost product is screened and bagged into $25 \mathrm{~kg}$ or $40 \mathrm{~kg}$ bags.

The investment cost for composting facilities depends on the choice of composting capacity and the level of automation [25]. Generally, the choice of optimal composting process and capacity needs to make a trade off among labor, land, and capital costs, plus other parameters.

Food waste in most cases is easy to degrade and may emit odor during collection and transportation. Considering the simple operation and low investment costs, and the odor emissions arising from the storage and collection of food waste, this paper suggests that the wholesale and retail systems may install biogas production units or composting plants. The food waste generated in the production institutions is delivered to the affiliated plant for production of biogas or composts. In such a case, transportation costs can be avoided and odor emissions can be reduced to a minimum.

\section{Conclusion}

This paper develops a simple calculation method to define recycling performance for each waste fraction. Through the comparison of recycling performance for each waste fraction, this paper finds that the recycling performance of waste metal ranks at the top due to the high market value of waste metal. In contrast, the recycling of food waste is found to meet a bottom neck as its recycling performance reaches a peak and then declines. The reduced performance for food wastes may be attributed to no market value and difficulty in storing and collecting food wastes. This paper suggests 2 instruments to remedy the recycling barriers of food wastes: 1) a tax is imposed on the food waste generated in the production process and 2) the productive institutions have to install their affiliated digestion or composting plants for recycling food waste. The installation of a digestion or composting plant for food waste may provide significant benefits to human and ecosystem health. The biogas or composts produced not only yield economic benefits but also reduce the environmental nuisance.

Increasing awareness of environmental degradation and the scarcity of resources have pushed the public to care more about the generation of waste and to engage in more saving behaviors. In this case, this paper suggests that environmental education is also required to educate the public for the commitment of green consumption. 
The environmental policy may consider the finding and the suggestion in this paper to form a more proactive policy by emphasizing 1) consumption saving directed by prevention principle and 2) the recovery of materials and the regeneration of energy from various waste fractions to achieve sustainable development. In practice, recycling of materials from sorting or recovery of energy from the incineration of municipal solid wastes may yield economic benefits for some interested parties involving MSW management. In practice, the recycling of waste paper, metals, and plastics contributes much to society for the increased employment and economic benefits in addition to the mitigation of environmental externalities. Economic attraction may play a more important role in changing human behaviors to engage in more clean production and green consumption. And thus, some mechanisms to motivate recycling performance through the cooperation of the interested parties in the recycling process, including collectors, material recovery plants, and incineration plants, are required. However, no incentive mechanism is designed and implemented currently to motivate interested parties to enhance the recycling of recyclables. A study may be extended to the issue in association with the incentive mechanisms in the future.

\section{Acknowledgment}

The research was supported in part by Ministry of Science and Technology under grant MOST 106-2410-H227-001 to Yi-Tui Chen.

\section{References}

1. MILLER JR. G.T. Environmental Science, $7^{\text {th }}$ edition, Belmont, CA: Wadsworth Publishing, 1999.

2. SHAKER R.R., SIRODOEV I.G. Assessing sustainable development across Moldova using household and property composition indicators. Habitat International, 55, 192, 2016.

3. LOREK S., SPANGENBERG J.H. Sustainable consumption within a sustainable economy e beyond green growth and green economies. J. Clean. Prod. 63, 33, 2014.

4. TAIWAN EPA. Taiwan's environmental policy, 2017. Web site: http://www.epa.gov.tw/ct.asp?xItem $=35369 \& \mathrm{CtNode}=$ $34117 \& \mathrm{mp}=\mathrm{epa}$

5. CHEN C.C., CHEN Y.T. Energy recovery or material recovery for MSW treatments, Resources, Conservation and Recycling 74, 37, 2013.

6. CHEN C.C. A performance evaluation of MSW management practice in Taiwan. Resources, Conservation \& Recycling, 54, 1353, 2010.

7. HARIJANI A.M., MANSOUR S., KARIMI B., LEE C.G. Multi-period sustainable and integrated recycling network for municipal solid waste e A case study in Tehran. Journal of Cleaner Production, 151, 96, 2017.

8. THITANUWAT B., POLPRASERT C., ENGLANDE JR. A.J. Green residues from Bangkok green space for renewable energy recovery, phosphorus recycling and greenhouse gases emission reduction. Waste Management, 61, 572, 2017.

9. STRUCK M. Distance and incentives matter: The separation of recyclable municipal waste. Resources, Conservation and Recycling, 122, 155, 2017.

10. CHIFARI R., PIANO S.L., MATSUMOTO S., TASAKI T. Does recyclables separation reduce the cost of municipal waste management in Japan? Waste Management, 60, 32, 2017.

11. SUKHOLTHAMAN P., SHARP A. A system dynamics model to evaluate effects of source separation of municipal solid waste management: A case of Bangkok, Thailand. Waste Management, 52, 50-61, 2016.

12. TAIWAN EPA. Yearbook of environmental protection statistics. Taipei, Taiwan EPA, 2016.

13. CHEN C.C. An evaluation of optimal application of government subsidies on recycling of recyclable waste. Polish Journal of Environmental Studies, 14 (2), 2005.

14. ADAMCOVÁ D., VAVERKOVÁ M.D., STEJSKAL B., BŘOUŠKOVÁ E. Household solid waste composition focusing on hazardous waste. Polish Journal of Environmental Studies, 25 (2), 487, 2016.

15. HARTMANN H., AHRING B.K. Strategies for the anaerobic digestion of the organic fraction of municipal solid wastes: an overview. Water Science and Technology 53, 7, 2006

16. ALI A., AZAM S., KHALID A., NOMAN D., JAMIL N., SAMINA F., SHAIKH I.A. End- of- life scenarios for municipal solid waste of defence housing authority lahore, Pakistan. Polish Journal of Environmental Studies, 26 (3), 961, 2017.

17. MOURAD M. Recycling, recovering and preventing "food waste": competing solutions for food systems sustainability in the United States and France. Journal of Cleaner Production, 126, 461, 2016.

18. EUROPEAN COMMISSION. Preparatory Study on Food Waste across EU 27, Technical Report 2010-054, European Commission, 2010.

19. ERIKSSON M., STRID I., HANSSON P.A. Food losses in six Swedish retail stores: Wastage of fruit and vegetables in relation to quantities delivered. Resources, Conservation and Recycling, 68, 14, 2012.

20. SEGARRA-OÑA M., PEIRÓ-SIGNES A., MONDÉJARJIMÉNEZ J. Identifying Variables Affecting the Proactive Environmental Orientation of Firms: An Empirical Study. Polish Journal of Environmental Studies, 22 (3), 873, 2013.

21. MATUSZAK-FLEJSZMAN A. Factors for improving environmental management systems in Polish companies according to ISO 14001. Polish Journal of Environmental Studies, 20 (3), 709, 2011

22. OBERSTEINER G., SCHNEIDER F., LEBERSORGER S. Potentials for the prevention of municipal solid waste. Waste Management, 28 (2), 245, 2008.

23. MCDOUGALL F., WHITE P., FRANKE M., HINDLE P. Integrated Solid Waste Management: A Life-Cycle Inventory, Blackwell Science, 2nd Edition, 2001.

24. THYBERG K.L.,TONJES D.J. The environmental impacts of alternative food waste treatment technologies in the U.S. Journal of Cleaner Production, 158 (1), 101, 2017.

25. CHEN Y.T. A Cost Analysis of Food Waste Composting in Taiwan. Sustainability, 8 (11), 1210, 2016. 
